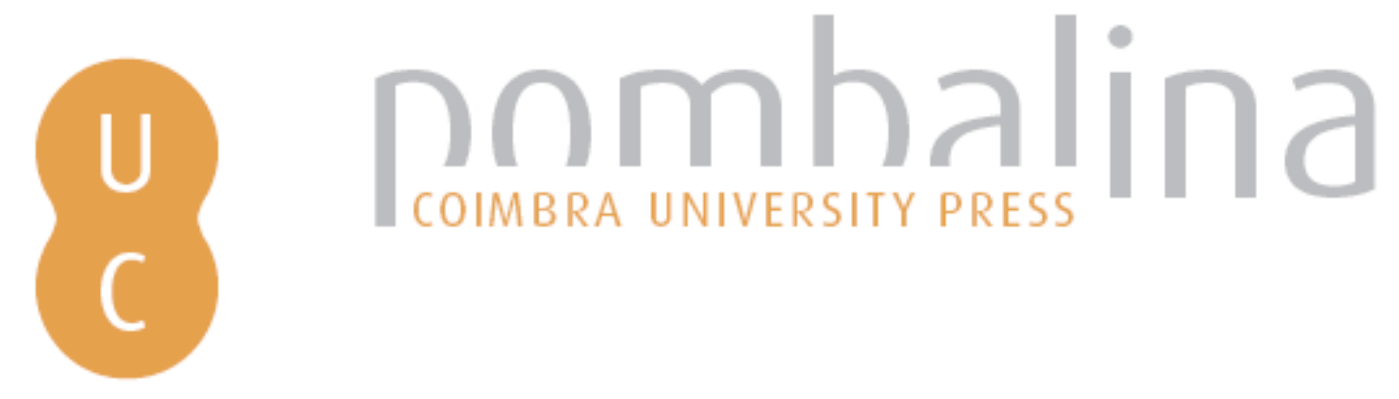

\title{
Fungos e bactérias
}

Autor(es): $\quad$ Seena, Sahadevan; Duarte, Sofia; Cássio, Fernanda; Sobral, Olímpia

Publicado por: Imprensa da Universidade de Coimbra

URL

persistente: URI:http://hdl.handle.net/10316.2/45882

DOI: $\quad$ DOl:https://doi.org/10.14195/978-989-26-1624-7_5

Accessed : $\quad$ 26-Apr-2023 15:36:01

A navegação consulta e descarregamento dos títulos inseridos nas Bibliotecas Digitais UC Digitalis, UC Pombalina e UC Impactum, pressupõem a aceitação plena e sem reservas dos Termos e Condições de Uso destas Bibliotecas Digitais, disponíveis em https://digitalis.uc.pt/pt-pt/termos.

Conforme exposto nos referidos Termos e Condições de Uso, o descarregamento de títulos de acesso restrito requer uma licença válida de autorização devendo o utilizador aceder ao(s) documento(s) a partir de um endereço de IP da instituição detentora da supramencionada licença.

Ao utilizador é apenas permitido o descarregamento para uso pessoal, pelo que o emprego do(s) título(s) descarregado(s) para outro fim, designadamente comercial, carece de autorização do respetivo autor ou editor da obra.

Na medida em que todas as obras da UC Digitalis se encontram protegidas pelo Código do Direito de Autor e Direitos Conexos e demais legislação aplicável, toda a cópia, parcial ou total, deste documento, nos casos em que é legalmente admitida, deverá conter ou fazer-se acompanhar por este aviso. 
MARIA JOÃO FEIO

VERÓNICA FERREIRA

(EDS.)

\section{IMPRENSA DA \\ UNIVERSIDADE \\ DE COIMBRA \\ COIMBRA \\ UNIVERSITY \\ PRESS}

\section{RIOS DE PORTUGAL COMUNIDADES, PROCESSOS E ALTERAÇÕES}




\title{
C A P ÍT ULO 5 \\ FUNGOS E BACTÉRIAS
}

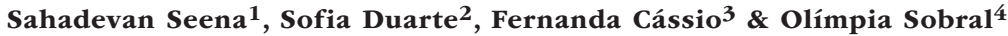

${ }^{1}$ MARE - Centro de Ciências do Mar e do Ambiente, Departamento de Ciências da Vida, Universidade de Coimbra, Portugal, seena.sahavedan@uc.pt ${ }^{2}$ CBMA - Centro de Biologia Molecular e Ambiental, Departamento de Biologia, Universidade do Minho, Portugal e IB-S - Instituto de Ciência e Inovação para a Bio-Sustentabilidade, Universidade do Minho, Portugal, sduarte@bio.uminho.pt ${ }^{3}$ CBMA - Centro de Biologia Molecular e Ambiental, Departamento de Biologia, Universidade do Minho, Portugal e IB-S - Instituto de Ciência e Inovação para a Bio-Sustentabilidade, Universidade do Minho, Portugal, fcassio@bio.uminho.pt ${ }^{4}$ MARE - Centro de Ciências do Mar e do Ambiente, Departamento de Ciências da Vida, Universidade de Coimbra, Portugal, osobral@uc.pt
\end{abstract}

Resumo: A principal fonte de matéria orgânica dos ribeiros de montanha são as folhas que se depositam sobre o leito maioritariamente durante o outono. Essas folhas vão passar por um processo de decomposição no qual os microorganismos aquáticos, em especial um grupo de fungos designado por hifomicetes, são os primeiros a atuar, pois conseguem quebrar moléculas complexas do material vegetal, tornando-o mais apetecível e fácil de digerir para outros organismos. Os hifomicetes aquáticos produzem uma grande quantidade de esporos que aderem facilmente ao material vegetal mesmo em águas agitadas. A biodiversidade dos hifomicetes aquáticos em Portugal tem sido mais estudada no norte e centro e mais recentemente na ilha de São Miguel, no arquipélago dos Açores. Foi já reportada 
a existência de 129 espécies, incluindo uma espécie descrita pela primeira vez na bacia do rio Cávado (Collembolispora barbata). Estes microorganismos são afetados pelas características da água havendo diferentes ocorrências consoante o nível de nutrientes, temperatura e/ou grau de contaminação existentes. Metais, compostos orgânicos e fármacos têm mostrado efeitos adversos sobre as comunidades de hifomicetes com alteração da biodiversidade e biomassa. Dentro das comunidades microbianas existem outros fungos filamentosos, fungos unicelulares (leveduras) e bactérias mas ainda há pouca informação sobre as suas funções no processo de decomposição. As técnicas moleculares são uma ferramenta promissora no estudo das comunidades microbianas e Portugal tem tido uma grande contribuição para o enriquecimento das bases de dados genéticas internacionais.

Palavras chave: bactérias, biodiversidade, contaminação antropogénica, decomposição, hifomicetes aquáticos

\section{Decompositores microbianos em rios e ribeiros}

A complexa rede de interações biológicas e químicas entre decompositores microbianos nem sempre é fácil de estudar, porém o reconhecimento da importância dos ecossistemas fluviais nos ciclos biológicos do carbono e dos nutrientes tem progredido nos últimos anos $^{1-5}$. Nos ecossistemas fluviais de floresta, particularmente nos cursos de água de cabeceira, onde a cobertura ripária abrange todo o leito, a principal fonte de carbono provém da queda das folhas e de outro material vegetal, sendo este um fator limitante para a incorporação de carbono na produção secundária ${ }^{6}$, isto é, organismos sem capacidade fotossintética (consumidores) ficam dependentes do processo de decomposição da matéria vegetal ${ }^{7-10}$ (Capítulo 12). Os microorganimos 
aquáticos, em particular um grupo de fungos designado por hifomicetes aquáticos, têm um papel fundamental neste processo iniciando a quebra de macromoléculas orgânicas; por exemplo, a celulose das paredes vegetais é separada em moléculas de açúcares simples e assimiláveis através da ação de exoenzimas (excretadas das células para o substrato onde ocorrem as quebras das ligações químicas). As bactérias são igualmente importantes neste processo, todavia a sua atuação sucede-se à dos fungos ${ }^{3,11}$. Este processo de decomposição da matéria orgânica vegetal pelos microorganismos, também designado por condicionamento das folhas, torna-a mais palatável e enriquecida em nutrientes para os macroinvertebrados aquáticos que as consomem ${ }^{12,13}$.

A presença de microorganismos aquáticos num determinado local não se resume a um aglomerado de diferentes espécies mas também a toda a sua rede de interações, formando comunidades microbianas complexas cuja função ecológica pode ser afetada por perturbações ambientais $^{14,15}$. Assim, é essencial avaliar e compreender os factores que promovem alterações na biodiversidade e consequentemente afetam a função da comunidade como um todo ${ }^{14}$. Apesar de ocorrerem alternâncias sazonais nos padrões de biodiversidade das comunidades microbianas ${ }^{14}$, são as alterações de origem antropogénica que geram preocupação sobre a manutenção da função ecológica e a extinção de espécies $^{16-17}$. A quebra do ciclo de decomposição da matéria orgânica vegetal, por perda de biodiversidade microbiana e desestruturação das comunidades, conduz a desequilíbrios mais ou menos pronunciados nos ecossistemas fluviais ${ }^{18}$, de acordo com as funções chave das espécies afetadas $^{19}$. Subsiste, portanto, uma questão relevante: será possível que os ecossistemas fluviais possam recuperar as suas funções ecológicas após a mitigação da perturbação a que foram sujeitos? A resposta encontra-se na biodiversidade e na intensidade e duração da pressão ambiental sofrida. A manutenção da função de uma comunidade depende do equilíbrio entre o estado fisiológico dos seus organismos (alocação dos recursos energéticos para crescimento, reprodução, reparação de danos) e a bio- 
diversidade e proporção das diferentes espécies que a compõem. Por um lado, os microorganismos têm mecanismos fisiológicos de aclimatação a alterações das condições ambientais, mas por outro lado, a diversidade genética das suas populações (diferentes estirpes) permite uma rápida adaptação em situações de forte pressão selectiva. Assim, quando se faz sentir uma pressão ambiental, seja ela natural ou antropogénica, que perturba esse equilíbrio inicial (levando, por exemplo, à diminuição de taxas reprodutivas e/ou ao aumento de mortalidade em espécies mais sensíveis) podem ocorrer rearranjos nas estratégias de vida e nas relações ecológicas (p.ex., espécies que nas novas condições ambientais são mais competitivas e eficientes) permitindo uma recuperação das funções do ecossistema à custa de alterações dos fluxos de energia e nutrientes ${ }^{20}$ e que podem repercutir-se nos níveis tróficos superiores devido a preferências alimentares dos macroinvertebrados aquáticos ${ }^{21}$.

Em Portugal têm sido desenvolvidos estudos, predominantemente nas zonas norte e centro do país, possibilitando uma compreensão mais sólida das comunidades microbianas e da relação biodiversidade/função ecológica dos fungos aquáticos, principalmente dos hifomicetes aquáti$\cos ^{22-26}$. Apesar das comunidades microbianas dos ecossistemas fluviais não estarem ainda satisfatoriamente compreendidas, podemos avançar que o modelo de "maior biodiversidade melhor o processo de mitigação dos efeitos da pressão ambiental" é seguido por estes microorganismos ${ }^{27,28}$.

\section{Hifomicetes aquáticos}

\subsection{Descoberta dos hifomicetes aquáticos e sua importância no processo de decomposição da matéria orgânica}

De entre os fungos aquáticos, os hifomicetes aquáticos constituem o grupo mais abundante nas folhas em decomposição em ribeiros 
de cabeceira ${ }^{29,30}$. Os hifomicetes aquáticos ou fungos Ingoldianos foram descritos pela primeira vez pelo Professor Cecil Terence Ingold, durante uma análise de amostras de água recolhidas num ribeiro que fluía perto de sua casa, em Inglaterra. A morfologia destes esporos assexuados foi usada por Ingold para identificar e descrever cerca de 30 espécies, e atualmente este continua a ser o método mais comummente usado na identificação de espécies de hifomicetes aquáticos.

Durante as suas observações, Ingold verificou que os hifomicetes aquáticos produziam grandes quantidades de esporos a partir de folhas em decomposição e que estes ficavam retidos nas espumas que se formam naturalmente nos ribeiros ${ }^{31}$. Estas observações levaram Ingold a constatar que os hifomicetes aquáticos são os principais agentes microbianos de reciclagem da matéria orgânica nos ribeiros, nomeadamente das folhas e dos galhos que caem da vegetação ribeirinha ${ }^{31}$. Estudos posteriores deram suporte a esta descoberta. Mal entram no ribeiro, estas folhas ou galhos são colonizados pelos hifomicetes aquáticos, que decompõem compostos presentes nas células vegetais, como a lenhina, a celulose, a hemicelulose e as pectinas ${ }^{29,30}$. Estes compostos são transformados em compostos mais simples e em minerais, que são mais facilmente digeríveis por outros organismos aquáticos que intervêm nas redes tróficas dependentes de detritos, como os invertebrados fragmentadores 29,30 . Os hifomicetes aquáticos constituem deste modo um elo crucial entre as folhas em decomposição e os fragmentadores ${ }^{29,30}$. Os esporos produzidos pelos hifomicetes aquáticos, com formas de estrela (forma tetraradiada ou multiradiada), meia-lua ou agulha (forma sigmoide) (Figura 5.1), aderem facilmente às folhas ou aos galhos em ambientes de elevada turbulência da água ${ }^{32}$. Esta característica, a juntar à elevada capacidade de crescerem e de se reproduzirem a temperaturas relativamente baixas, comummente encontradas em ribeiros das regiões temperadas durante a queda das folhas no outono, fazem com que este grupo de fungos domine sobre os restantes microorganismos no processo de decomposição 29,30 . 


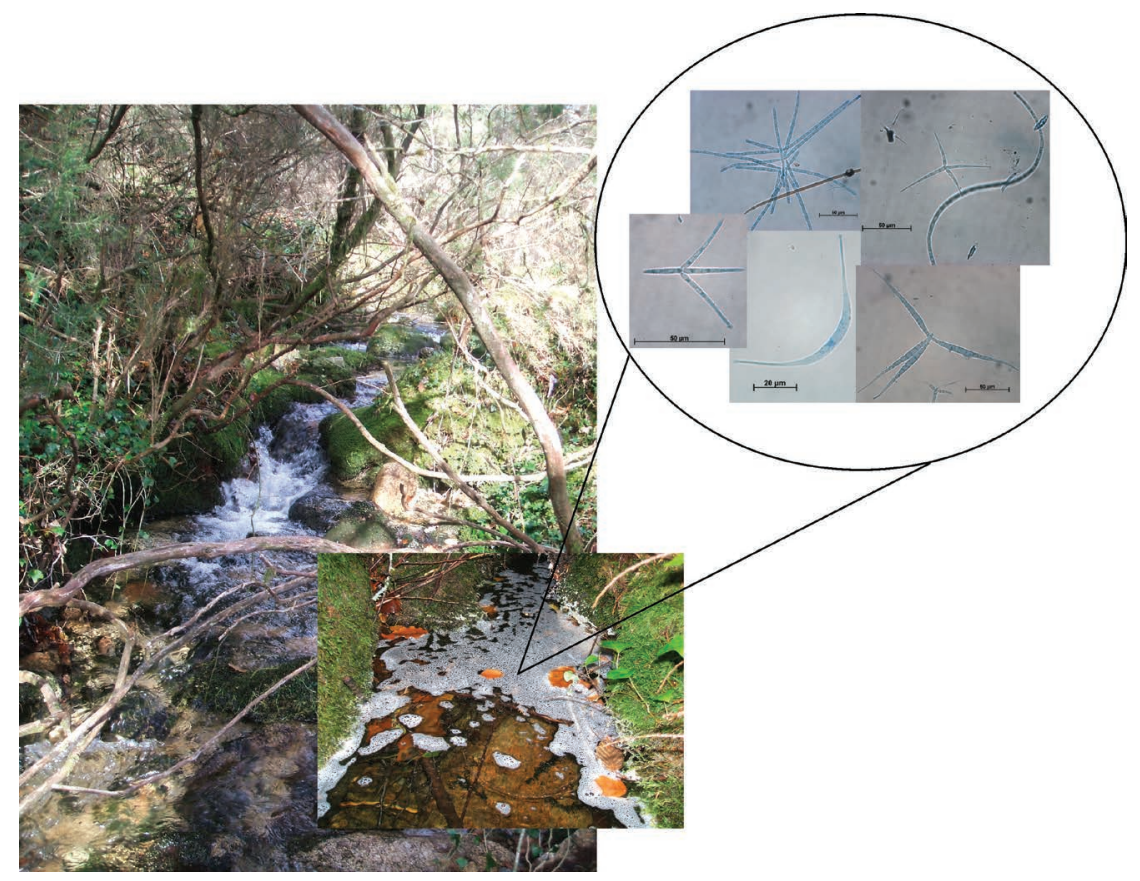

Figura 5.1. Esporos com formas de estrela, meia-lua ou agulha (com tamanhos entre 20 e $200 \mu \mathrm{m} ; 1 \mu \mathrm{m}=0,001 \mathrm{~mm}$ ) produzidos pelos hifomicetes aquáticos encontrados nas folhas e nos galhos em decomposição e na água ou nas espumas que se formam naturalmente nos rios e ribeiros. Fotografias: Sofia Duarte.

Assim que as folhas caem nos rios e ribeiros, os fungos aquáticos rapidamente iniciam a sua colonização atingindo picos de reprodução (esporulação - produção de grande quantidade de esporos que podem chegar aos milhões) e picos de biomassa fúngica ${ }^{3,33-35}$. Comummente, a colonização por fungos acompanha a decomposição microbiana das folhas 33,36 . No entanto, de uma forma geral, os picos de esporulação são atingidos mais cedo durante o processo de decomposição das folhas e sofrem um declínio mais abruto, enquanto os picos de biomassa são geralmente mantidos durante um período de tempo superior e sofrem um declínio mais gradual, à medida que as folhas vão sendo decompostas pelos microorganismos $33,34,37,38$. 
Os tempos de colonização e os tempos para que estes picos máximos de atividade sejam atingidos pode ser bastante variável $33,37,39$. Por exemplo, os picos de esporulação podem ser atingidos logo após 2 semanas de imersão das folhas no rio $^{33}$ ou mais tardiamente, por exemplo, apenas após 12 semanas $^{37}$, dependendo de uma série de fatores tais como a identidade das folhas ${ }^{36,38-40}$ e da vegetação ribeirinha ${ }^{41}$, assim como de outros fatores ambientais tais como a temperatura ${ }^{38,42}$, a concentração de nutrientes $3,33,43-46$ e a presença de contaminantes na água ${ }^{43,47}$. Em rios e ribeiros portugueses, a colonização por fungos tem-se mostrado mais retardada, e como tal os picos máximos de atividade atingidos mais tardiamente, em folhas mais recalcitrantes tais como folhas de eucalipto (Eucalyptus globulus) e de carvalho (Quercus robur), relativamente a folhas mais moles e ricas em nutrientes tais como folhas de amieiro (Alnus glutinosa) e de castanheiro (Castanea sativa) ${ }^{36,41,46}$. Níveis moderados de nutrientes na água também parecem estimular as taxas de esporulação e biomassa de fungos $3,33,44-46$, enquanto a presença de contaminantes na água, tal como metais pesados, parecem reduzir fortemente as taxas de esporulação e a biomassa, assim como alterar as dinâmicas de colonização das folhas pelos fungos ${ }^{43,47}$. Já a temperatura, que é um fator conhecido por afetar fortemente a ocorrência e distribuição dos hifomicetes aquáticos, tem tido efeitos contraditórios na atividade de fungos aquáticos que parecem variar com outros fatores. Por exemplo, o aumento de $7^{\circ} \mathrm{C}$, em experiências de laboratório mas usando comunidades de fungos naturais, reduziu as taxas de esporulação ${ }^{42}$. No entanto, um aumento de aproximadamente $3^{\circ} \mathrm{C}$ estimulou as taxas de esporulação e a biomassa de fungos em folhas de castanheiro ${ }^{48}$, mas não em folhas de carvalho ${ }^{35,48}$. Já as dinâmicas não parecem diferir significativamente entre tratamentos expostos a diferentes temperaturas ${ }^{35,42}$, mas alterações ligeiras foram encontradas entre diferentes estações do ano (picos mais tardios no outono e no inverno do que na primavera) ${ }^{35}$. 


\subsection{Distribuição dos hifomicetes aquáticos em rios e ribeiros}

Ingold dedicou-se durante mais de 30 anos ao estudo dos hifomicetes aquáticos e reportou a sua presença em diferentes regiões do mundo (p.ex., Europa ${ }^{49}$, África ${ }^{50}$, América do Norte ${ }^{51}$ ). Muitos outros estudos se seguiram, contribuindo para a assunção de que os hifomicetes aquáticos possuem uma distribuição global e que também abundam em ribeiros de regiões tropicais ${ }^{52}$.

Atualmente existem cerca de 300 espécies descritas, com base na morfologia dos esporos ${ }^{53}$. De entre os países Europeus, Portugal encontra-se entre os mais estudados, com uma biodiversidade de 129 espécies de hifomicetes aquáticos (Figura 5.2, Tabela 5.1). Até à data foram contabilizadas cerca de 39 publicações, em que a biodiversidade de hifomicetes aquáticos foi investigada na água ${ }^{24,54}$, em espumas 55 e em folhas em decomposição ${ }^{39,55}$. Estes estudos tiveram uma maior incidência no norte e no centro de Portugal, com um número de espécies muito similar nas duas regiões (103 e 102 espécies no norte e no centro, respetivamente) (Tabela 5.1). Os estudos foram conduzidos maioritariamente nas bacias hidrográficas dos rios Cávado ${ }^{33,55}$, Ave $^{44,55}$, Douro ${ }^{56}$, Vouga $^{24}$ e Mondego ${ }^{24}$. Recentemente também foram reportadas 28 espécies em ribeiros da ilha de São Miguel, no arquipélago dos Açores ${ }^{39}$, mas as restantes ilhas assim como as do arquipélago da Madeira encontram-se por explorar. De facto, grande parte do território português encontra-se ainda por estudar, não havendo publicações sobre a ocorrência de hifomicetes aquáticos na Estremadura, Ribatejo, Alentejo e Algarve.

Com base nas publicações de estudos conduzidos entre 1995 e 2016, cerca de 16 espécies tiveram uma ocorrência frequente (Figura 5.2, Tabela 5.1), sendo as espécies Alatospora acuminata, Articulospora tetracladia, Anguillospora filiformis e Lunulospora curvula as que apresentam um maior número de ocorrências (Figura 5.2). A maioria destas espécies registadas em Portugal apresenta uma 
distribuição cosmopolita, ou seja, a sua presença tem sido reportada em diversos estudos conduzidos em outras regiões do mundo 52 . No entanto, também temos espécies raras tais como Flagellospora curta, Geniculospora grandis, Heliscus submersus e Tetracladium palmatum $^{55,57}$ e a espécie Collembolispora barbata ${ }^{57}$ cuja ocorrência foi reportada e descrita pela primeira vez em Portugal, na bacia hidrográfica do rio Cávado.

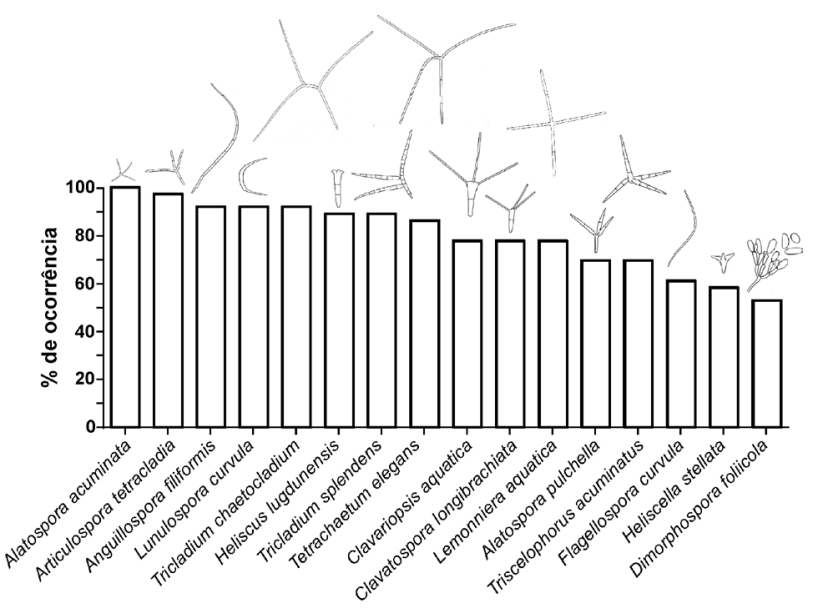

Figura 5.2. Espécies de hifomicetes aquáticos com maior número de ocorrências nas publicações de estudos conduzidos em rios e ribeiros portugueses (ocorrência em mais do que $50 \%$ das publicações). As formas dos esporos foram

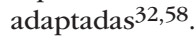




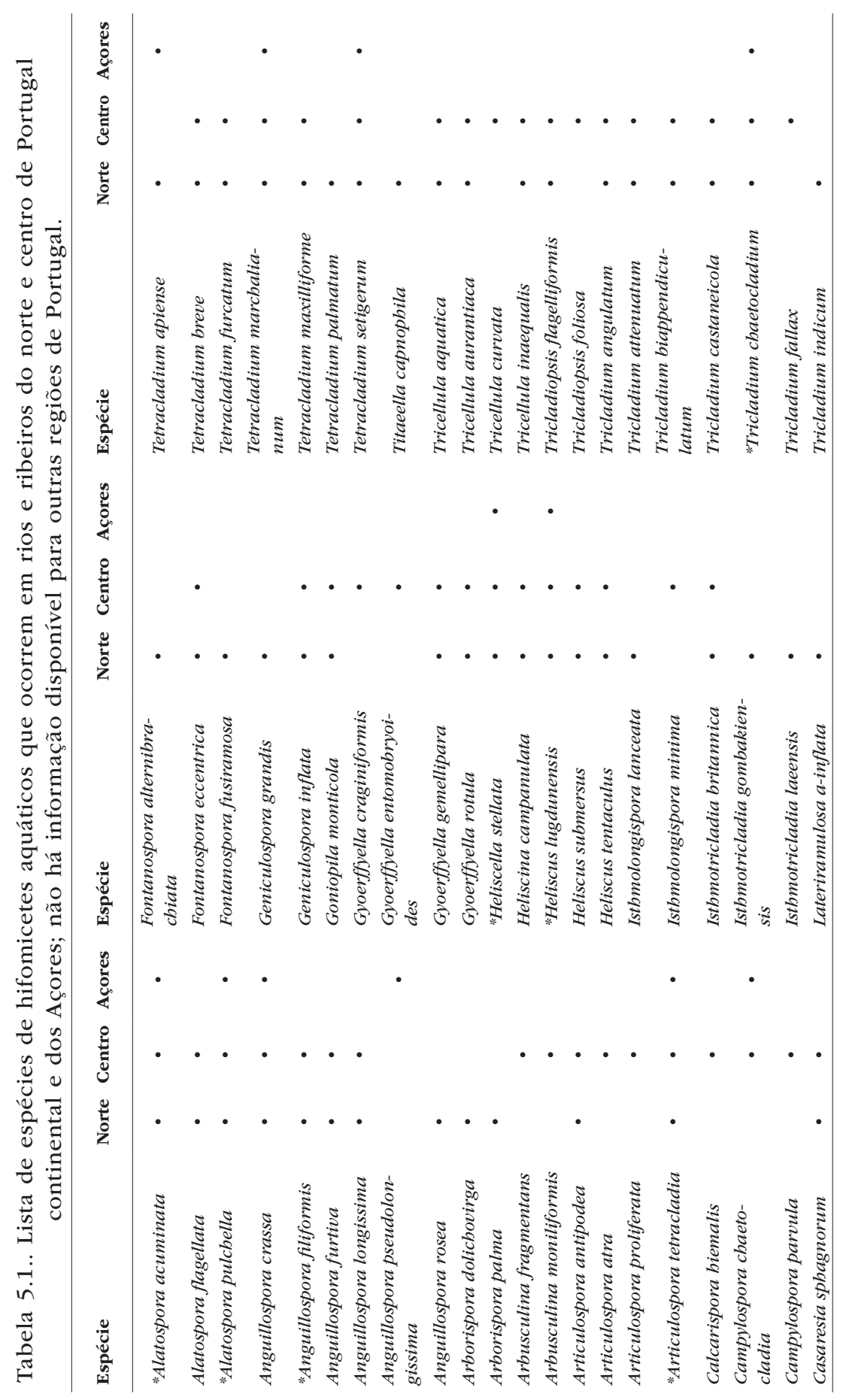




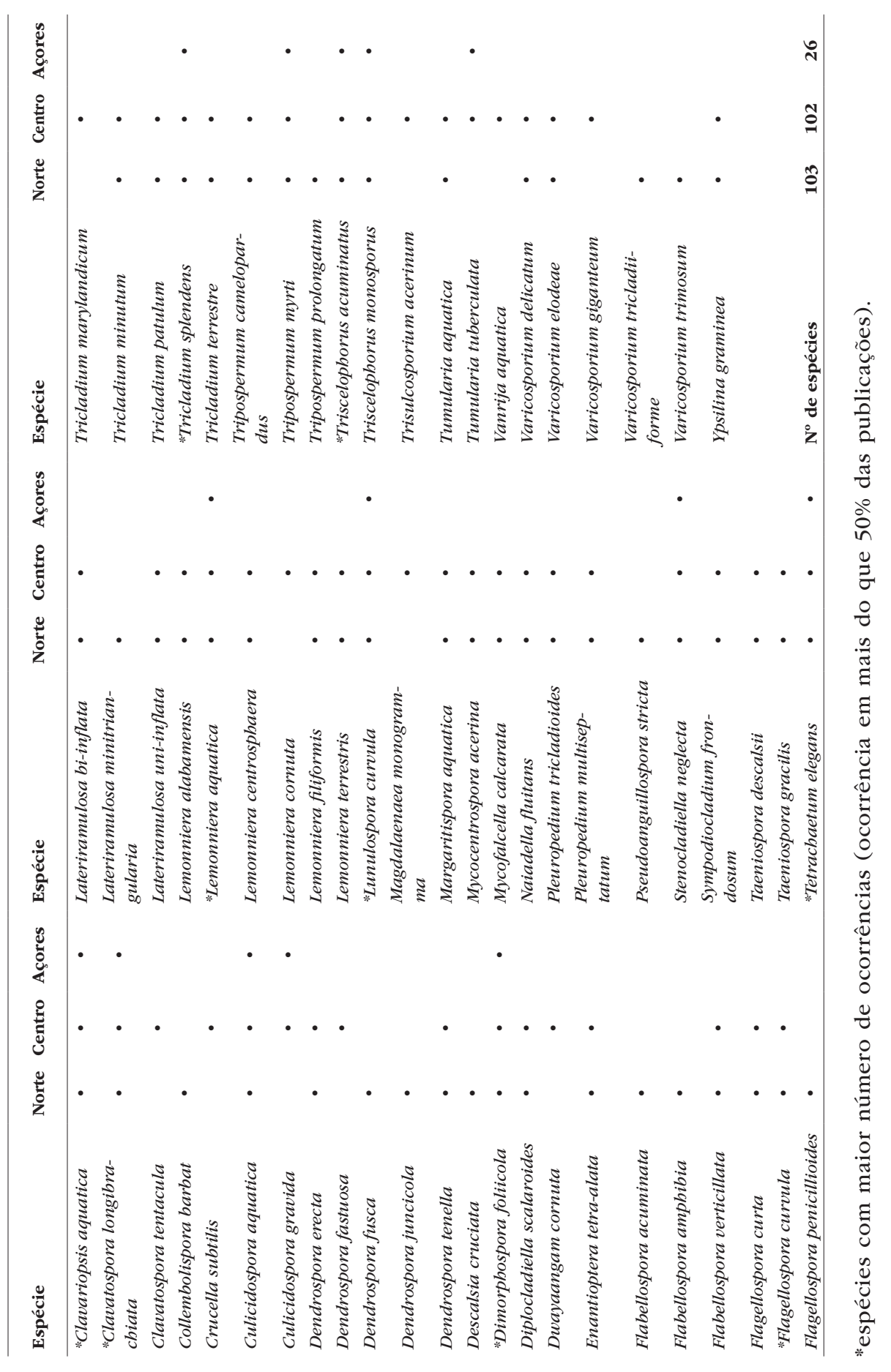




\section{Leveduras e outros fungos aquáticos}

Para além dos hifomicetes aquáticos, as leveduras (fungos unicelulares) e outros fungos filamentosos também estão associados à decomposição das folhas 59,60 . Os poucos estudos desenvolvidos sobre leveduras nos rios e ribeiros portugueses encontraram espécies ubíquas e persistentes ao longo do processo de decomposição (p.ex., Cryptococcus albidus, Debaryomyces hansenii e Rhodothorula glutinis) em diversos tipos de folhas (amieiro, carvalho e eucalipto), enquanto outras apenas se desenvolvem em determinadas fases do processo, sugerindo um padrão de sucessão ecológica ${ }^{60}$.

Outros fungos filamentosos como Mortierella sp., Cladosporium sp., Penicillium sp. e Aspergilus sp., também foram encontrados associados à decomposição das folhas em sistemas aquáticos, mas a sua participação no processo é questionável. O estudo de Graça e Ferreira ${ }^{1}$ sugere que estes fungos filamentosos, considerados terrestres, são incapazes de macerar as folhas em ambientes aquáticos (i.e., quando submersos).

\section{Bactérias}

Nos ecossistemas fluviais os fungos são os principais atores no processo de decomposição das folhas ${ }^{2,3}$ mas as bactérias não podem ser esquecidas. As bactérias são responsáveis pela decomposição da matéria orgânica que se encontra nos espaços intersticiais de sedimentos finos ${ }^{61,62}$, porém poucos estudos foram realizados para compreender quais os tipos de bactérias envolvidas neste processo. As técnicas moleculares permitem uma melhor recolha de dados sobre biodiversidade bacteriana e os efeitos das condições ambientais sobre as comunidades bacterianas. Por exemplo, numa experiência levada a cabo no Ribeiro de Candal (Serra da Lousã) foi observado um aumento de 38 para 47 OTUs (unidades taxonó- 
micas operacionais - baseadas na similaridade de ADN) em folhas de carvalho quando a temperatura da água foi aumentada em $3{ }^{\circ} \mathrm{C}$ acima da temperatura ambiente ${ }^{63}$. Também foram usadas técnicas moleculares para estudar o efeito da contaminação por metais num estudo realizado em laboratório onde se verificou a diminuição de OTUs nas comunidades bacterianas expostas quer a metais na sua forma iónica ou na forma de nanopartículas ${ }^{64}$.

\section{Principais agentes de stress antropogénico e os seus im- pactos nos fungos e bactérias}

\subsection{Efeito do enriquecimento em nutrientes}

A atividade dos fungos associados às folhas é estimulada pela presença de concentrações moderadas de azoto (N) e fósforo (P) na água do rio, mas inibida a concentrações elevadas ${ }^{65-67}$. Especificamente, a reprodução e a biomassa dos fungos parece ser estimulada em ribeiros com níveis moderados de eutrofização (enriquecidos em $\mathrm{N}$ e P) mas inibidas em ribeiros oligotróficos ou hipertróficos ${ }^{67}$. Num estudo simultâneo em ribeiros portugueses e franceses com níveis diferentes de eutrofização, o número de espécies de fungos foi máximo nos ribeiros moderadamente eutróficos, mas diminuiu nos ribeiros hipertróficos ${ }^{33}$. Em ambas as áreas geográficas, $\mathrm{O}$ nutriente limitante, $\mathrm{N}$ ou $\mathrm{P}$, estimulou a atividade microbiana em rios de estado trófico moderado. Nos ribeiros hipertróficos, a biomassa e a reprodução dos fungos foram menores, e a biomassa bacteriana diminuiu drasticamente no local com maior concentração de amónia. Nos diferentes ribeiros verificou-se que a comunidade de fungos diferia com o nível de eutrofização do rio, com consequências para a atividade decompositora. 


\subsection{Efeito das alterações climáticas}

Os cenários de mudanças climáticas prevêem um aumento da temperatura global e alterações nos regimes de precipitação que podem alterar as concentrações de nutrientes e de poluentes/contaminantes nos rios. Numa experiência em microcosmos com comunidades microbianas naturais em que se examinaram os efeitos concomitantes do aumento da temperatura, da concentração de nutrientes inorgânicos na água do rio e da qualidade dos detritos vegetais na atividade microbiana e na decomposição das folhas mostrou-se que a captação do azoto da água foi maior em folhas com razão carbono/azoto (C/N) menor, como é o caso do amieiro, do que nas folhas com razão C/N maior, como é o caso do carvalho. A decomposição das folhas, a acumulação de biomassa e a reprodução dos fungos foram pouco afetadas pela concentração de $\mathrm{P}$ na água, mas a atividade microbiana aumentou até estabilizar com o aumento da concentração de N. O aumento da temperatura levou a um aumento na atividade máxima dos fungos e a uma diminuição da concentração de $\mathrm{N}$ necessária para alcançá-la, especialmente nas folhas de amieiro ${ }^{68}$.

No cenário de aquecimento global previsto, a decomposição das folhas pode tornar-se mais rápida em ribeiros com menores níveis de nutrientes, especialmente aqueles que recebem detritos de alta qualidade. Isso pode ser parcialmente explicado pelos efeitos de temperatura na atividade dos fungos 69,70 . A atividade microbiana tende a ser estimulada pela temperatura e algumas espécies de fungos, como Heliscus submersus, Lunulospora curvula e Varicosporium elodeae, apresentam atividade máxima a temperaturas elevadas (até $\left.27^{\circ} \mathrm{C}\right)^{70}$. No entanto, o efeito do aumento da temperatura da água na atividade dos hifomicetes aquáticos como um todo depende de múltiplos outros factores, incluindo tipo de folhas, estação do ano, presença de invertebrados e provavelmente também das características químicas da água ${ }^{71-73}$. 


\subsection{Efeito de alterações na floresta}

A diversidade em recursos alóctonos, provenientes da vegetação ribeirinha, também pode influenciar os microorganismos aquáticos. A atividade microbiana, nomeadamente o consumo de oxigénio, a biomassa, a reprodução e o número de espécies de fungos não foram sensíveis ao número de espécies de plantas nativas mas sim à identidade das espécies foliares presentes ${ }^{74}$. Isto é consistente com o encontrado em experiências em ribeiros do norte de Portugal, onde a atividade microbiana estava correlacionada positivamente com o conteúdo inicial de $\mathrm{N}$ das folhas ${ }^{75,76}$ e negativamente com o conteúdo de lenhina ${ }^{77}$. A biomassa e a diversidade dos fungos aquáticos nas folhas de eucalipto não parecem diferir substancialmente da associada a folhas de espécies nativas ${ }^{78}$. Contudo, a dinâmica de colonização e de reprodução dos fungos decompositores estavam alteradas devido à presença de óleos nas folhas de eucalipto que atrasam a sua colonização. Num estudo em microcosmos, onde foram avaliados os impactos ao longo de várias gerações microbianas, usando como ponto de partida um conjunto de espécies de uma floresta mista (amieiro, carvalho e eucalipto) colonizadas por comunidades naturais num ribeiro mostraram que a diversidade molecular de fungos e de bactérias diminuía com a perda da diversidade foliar ${ }^{79}$.

A diversidade de fungos aquáticos e a sua atividade decompositora são controlados pela diversidade e composição da vegetação ribeirinha $24,80,81$, mas também pelo estado de desenvolvimento da vegetação ribeirinha ${ }^{25}$, com implicações nas estratégias de gestão e restauração dos ecossistemas ribeirinhos. As espécies exóticas podem modificar a estrutura e o funcionamento dos ecossistemas porque elas modificam as condições abióticas (disponibilidade em luz, nível de nutrientes, transferência de calor, complexidade do habitat e perturbação física) e as interações 
bióticas e, assim, afetam vários atributos das comunidades nativas, como a diversidade, a distribuição, a densidade e a biomassa ${ }^{78}$. Atualmente, uma grande área da vegetação autóctone e caducifólia das nossas bacias hidrográficas foi substituída por plantações de eucalipto, originário da Austrália, que sendo uma floresta perenifólia altera a periodicidade e quantidade das folhas que entram nos cursos de água, assim como diminui a qualidade nutricional das folhas (menor conteúdo em $\mathrm{N}$ e P) disponíveis para os decompositores ${ }^{78}$. Num estudo feito sobre a ação dos fungos aquáticos nas folhas de eucalipto mostrou que, apesar de o número de espécies de fungos aquáticos serem semelhantes comparativamente a folhas de amieiro, as ceras da cutícula do eucalipto funcionavam como uma barreira à colonização dos fungos ${ }^{82}$, retardando-a em 2 semanas. A ação das ceras e outros óleos foi confirmada com experiências laboratoriais, onde folhas de eucalipto sujeitas à remoção química dos lípidos igualavam o tempo de colonização em amieiro ${ }^{83}$. No entanto, a taxa de decomposição das folhas de eucalipto mostrou-se dependente da quantidade de nutrientes da água; em águas oligotróficas a taxa de decomposição era mais baixa mas em águas mais ricas em nutrientes a taxa de decomposição era semelhante à do amieiro $^{41,78}$. Os trabalhos sobre esta temática sugerem que o efeito das plantações de eucaliptos mas comunidades microbianas poderá ser mitigado pela manutenção de uma margem de árvores nativas caducifólias ${ }^{41,81}$. Porém, nem só o eucalipto é problemático para a saúde dos ecossistemas aquáticos. Nos Açores a substituição de floresta nativa de Laurissilva por coníferas, como por exemplo a Araucária-do-Japão, é também motivo de preocupação ecológica, uma vez que a estrutura das comunidades de fungos aquáticos é alterada havendo uma redução da diversidade comparativamente a ribeiros de características semelhantes mas ainda com a floresta nativa de Laurissilva ${ }^{84}$. 


\subsection{Efeito de contaminantes persistentes e emergentes}

Uma abordagem em microcosmos no laboratório usando folhas pré-colonizadas por microorganismos na nascente do rio Este (noroeste de Portugal) mostrou que o zinco inibia a decomposição das folhas de amieiro por fungos aquáticos e afetava a estrutura das comunidades de hifomicetes aquáticos, embora o número de espécies e a biomassa de fungos não tenham sido afetadas ${ }^{85}$. No entanto, em ribeiros poluídos por metais, a diversidade de fungos aquáticos é baixa em comparação com os ribeiros não alterados 86 . A poluição por metais afeta as comunidades de fungos dependendo da identidade e da concentração do metal, e os efeitos parecem ser menos pronunciados nas comunidades adaptadas ao metal ${ }^{56}$. $\mathrm{O}$ zinco e o cobre juntos alteram a estrutura das comunidades de fungos e de bactérias, reduzem a reprodução de fungos, a biomassa bacteriana e as taxas de decomposição das folhas ${ }^{47}$. Os resultados sugerem também que uma maior diversidade de fungos apresenta uma maior capacidade de mitigar o impacto da poluição por metais na decomposição dos detritos vegetais dos ribeiros ${ }^{27}$ e contribui para aumentar a estabilidade do processo ${ }^{87}$. Vários estudos têm sugerido que as comunidades de fungos aquáticos podem responder ao stress de acordo com o modelo de redundância, em que a função permanece porque o aumento da biomassa de espécies tolerantes compensa a perda de espécies sensíveis em situações de stress ${ }^{43}$.

A urbanização e as atividades industriais têm contribuído para a contaminação por metais e hidrocarbonetos aromáticos policíclicos dos cursos de água. Contudo, os efeitos destes tóxicos em mistura nos organismos aquáticos e nos processos são pouco conhecidos. A exposição ao cádmio e/ou ao fenantreno no laboratório diminuiu a diversidade de fungos aquáticos. Além disso, o aumento das concentrações de cádmio diminuiu a reprodução de fungos e a decomposição das folhas, mas não inibiu a produção de biomassa dos fungos ${ }^{88}$. A 
exposição ao fenantreno potenciou os efeitos negativos do cádmio na diversidade e na atividade dos fungos, sugerindo que a co-ocorrência destes agentes de stress pode constituir um risco adicional para a biodiversidade aquática e para o funcionamento dos ecossistemas de rio.

$\mathrm{O}$ uso extensivo de produtos à base de nanomateriais aumenta a probabilidade da sua libertação nos ambientes aquáticos, levantando a questão de saber se estes contaminantes podem representar um risco para os organismos aquáticos e para os processos ecológicos por eles conduzidos ${ }^{89}$. Os metais nas formas nano e iónica inibem mais a biomassa bacteriana do que a biomassa dos fungos ${ }^{90}$. A exposição a concentrações aumentadas de metais nano e iónicos no laboratório diminuiu marcadamente a produção de esporos pelos fungos (mais de 90\%). Esses efeitos foram acompanhados por mudanças na comunidades dos fungos e das bactérias. Os impactos das nanopartículas metálicas na decomposição das folhas por microorganismos aquáticos foram menos pronunciados do que os efeitos das suas formas iónicas, apesar de os iões metálicos terem sido aplicados em concentrações muito mais baixas.

Os efeitos das nanopartículas (NPs) metálicas podem fazer-se sentir a níveis tróficos superiores, uma vez que foi observada uma inibição significativa da taxa de consumo de folhas (até $47 \%$ ) e na taxa de crescimento de invertebrados fragmentadores (até 46\%) quando expostos a nano-óxido de cobre (nanoCuO, $75 \mathrm{mg} / \mathrm{L}$ ), quer através da água contaminada ou das folhas contaminadas ${ }^{91}$. A exposição a nanoCuO levou a uma acumulação elevada de cobre no corpo do animal. O nanoCuO reduziu a taxa de decomposição das folhas e a biomassa dos fungos e das bactérias, a esporulação e a diversidade dos fungos associados às folhas em decomposição ${ }^{90}$. Os efeitos foram mais fortes à medida que o tamanho das nanopartículas diminuiu e a sua área de superfície específica aumentou. Além disso, o ácido húmico, usado como um indicador da matéria orgânica nos rios, atenuou a toxicidade das nanopartículas de $\mathrm{CuO}$ 
mais pequenas na decomposição das folhas pelos microorganismos. Por outro lado, as nanopartículas de prata (AgNPs) dispersas com PVP (polivinilpirrolidona) foram mais estáveis que as AgNPs não revestidas. Estes resultados destacam a importância de considerar as propriedades físico-químicas das NPs quando se avalia a sua toxicidade em processos que ocorrem nos rios, nomeadamente na decomposição dos detritos vegetais ${ }^{92}$. Concentrações mais elevadas de AgNPs e $\mathrm{AgNO}_{3}$ inibiram a reprodução e a diversidade de fungos, particularmente a temperaturas mais elevadas $\left(23^{\circ} \mathrm{C}\right)$. As atividades das enzimas extracelulares fenol oxidase e $\beta$-glucosidase foram geralmente maiores a $23^{\circ} \mathrm{C}$. As comunidades de fungos foram principalmente estruturadas pelas concentrações de $\mathrm{AgNPs}_{\text {e }} \mathrm{AgNO}_{3}$ em relação à temperatura. Os efeitos negativos dos contaminantes sobre a atividade microbiana foram mais pronunciados a 10 e $23^{\circ} \mathrm{C}^{93}$.

O consumo global de fármacos está também a aumentar devido sobretudo ao crescimento e envelhecimento da população humana e à produção intensiva de alimentos ${ }^{94}$. O aumento do consumo de antibióticos aumenta a preocupação com a saúde pública e com o ambiente 95 . Dada a importância das comunidades microbianas para assegurar as processos e os serviços dos ecossistemas ribeirinhos, os estudos dos efeitos de poluentes persistentes e emergentes em comunidades de microorganismos podem ser úteis como ferramenta para avaliar os efeitos destes contaminantes e as suas implicações potenciais para a saúde e para os ecossistemas ${ }^{96}$.

\section{Utilização de técnicas moleculares na deteção de fungos aquáticos}

Recentemente, através da aplicação de técnicas moleculares de última geração, também se verificou uma diminuição na biodiversidade de hifomicetes aquáticos nas folhas em decomposição e alterações 
ao nível da estrutura das comunidades em ribeiros no norte de Portugal, com elevados níveis de nutrientes incluindo amónia e nitritos ${ }^{44}$. Estas técnicas mostram-se bastante promissoras na medida em que foram capazes de discriminar populações geneticamente diferentes da espécie Articulospora tetracladia, presentes em rios com diferentes graus de eutrofização ${ }^{44}$. A descoberta de populações

geneticamente distintas 97 , entre indivíduos da mesma espécie, tem vindo a revolucionar a forma como a biodiversidade deverá ser acedida, nomeadamente em estudos acerca dos efeitos da biodiversidade de espécies no funcionamento dos ecossistemas ${ }^{98}$. Em estudos conduzidos em laboratório, a decomposição de folhas de amieiro por isolados geneticamente diferentes da espécie Articulospora tetracladia, obtidos de ribeiros portugueses com diferentes graus de poluição por metais pesados, diferiu significativamente na presença de cádmio ${ }^{98}$. Deste modo, o uso concomitante de técnicas tradicionais e moleculares deverá constituir uma mais-valia para avaliar a biodiversidade de hifomicetes aquáticos e estudar mais profundamente de que modo é que as alterações globais poderão afetar o funcionamento dos ribeiros. No entanto, para que o potencial destas metodologias de ultima geração possa ser explorado ao máximo e a identificação de espécies em amostras ambientais seja o mais eficiente possível, torna-se crucial a existência de bibliotecas contendo sequências de ADN de referência - DNA barcodes - de espécies de hifomicetes aquáticos. Neste campo, Portugal encontra-se na linha da frente, uma vez que mais de $50 \%$ das espécies de hifomicetes aquáticos com DNA barcode nas bases de dados genéticas internacionais foram isoladas de ribeiros Portugueses.

\section{Outras leituras}

International Plant Protection Convention: www.ippc.int/en/

Millenium Ecosystem Assessment: www.millenniumassessment.org/en/index.html 


\section{Referências bibliográficas}

${ }^{1}$ Graça M.A.S. \& Ferreira R. 1995. The ability of selected aquatic hyphomycetes and terrestrial fungi to decompose leaves in freshwater. Sydowia 47: 167-222

${ }^{2}$ Abelho M. 2001. From litterfall to breakdown in streams: a review. The Scientific World J. 1: 656-680

${ }^{3}$ Pascoal C. \& Cássio F. 2004. Contribution of fungi and bacteria to leaf litter decomposition in a polluted river. Appl. Environ. Microbiol. 70: 5266-5273

${ }^{4}$ Ferreira V., Lírio A.V., Rosa J. \& Canhoto C. 2013. Ann. Limnol. - Int. J. Limnol. 9: 13-19

${ }^{5}$ Solagaistua L., Arroita M., Aristi I., Larrañaga A. \& Elosegi A. 2016. Changes in discharge affect more surface than subsurface breakdown of organic matter in a mountain stream. Mar. Freshwat. Res. 67: 1826-1834

${ }^{6}$ Wallace J.B., Eggert S.L., Meyer J.L. \& Webster J.R. 1997. Multiple trophic levels of a forest stream linked to terrestrial litter inputs. Science 277: 102-104

${ }^{7}$ Cummins K.W. 1974. Structure and function of stream ecosystems. BioScience 24: 631-641

${ }^{8}$ Fisher S.G. \& Likens G.E. 1973. Energy flow in Bear Brook, New Hampshire: an integrative approach to stream ecosystem metabolism. Ecol. Monogr. 43: 421-439

${ }^{9}$ Vannote R.L., Minshall G.W., Cummins K.W., Sedell J.R. \& Cushing C.E. 1980. The river continuum concept. Can. J. Fish. Aq. Sci. 37: 130-137

${ }^{10}$ Webster J.R. \& Meyer J.L. 1997. Stream organic matter budgets: an introduction. J. N. Am. Benthol. Soc. 16: 3-13

${ }^{11}$ Gessner M.O., Chauvet E. \& Dobson M. 1999. A perspective on leaf litter breakdown in streams. Oikos 85: 377-384

${ }^{12}$ Graça M.A.S. 2001. The role of invertebrates on leaf litter decomposition in streams - a review. Int. Rev. Hydrobiol. 86: 383-393

${ }^{13}$ Petersen R.C. \& Cummins K.W. 1974. Leaf processing in a woodland stream. Freshwat. Biol. 4: 343-368

${ }^{14}$ Fuhrman J.A. 2009. Microbial community structure and its functional implications. Nature 459: 193-199

${ }^{15}$ Widder S., Allen R.J., Pfeiffer T., Curtis T.P., Wiuf C., Sloan W.T., Cordero O.X., Brown S.P., Momeni B. \& Shou W. 2016. Challenges in microbial ecology: building predictive understanding of community function and dynamics. The ISME Journal 10: 2557

${ }^{16}$ Young R.G., Matthaei C.D. \& Townsend C.R. 2008. Organic matter breakdown and ecosystem metabolism: functional indicators for assessing river ecosystem health. J. N. Am. Benthol. Soc. 27: 605-625

${ }^{17}$ Millennium Ecosystem Assessment 2005. Ecosystems and human well-being: wetlands and water. World resources institute. Island Press. USA, Washington, DC

${ }^{18}$ Gessner M.O. 2010. Functional leaf traits and biodiversity effects on litter decomposition in a stream: reply. Ecology 91: 1869-1871

${ }^{19}$ Gessner M.O., Swan C.M., Dang C.K., McKie B.G., Bardgett R.D., Wall D.H. \& Hättenschwiler S. 2010. Diversity meets decomposition. Trends Ecol. Evol. 25: $372-380$ 
${ }^{20}$ Schimel J., Balser T.C. \& Wallenstein M. 2007. Microbial stress-response physiology and its implications for ecosystem function. Ecology 88: 1386-1394

${ }^{21}$ Arsuffi T. \& Suberkropp K. 1989. Selective feeding by shredders on leaf-colonizing stream fungi: comparison of macroinvertebrate taxa. Oecologia 79: 30-37

${ }^{22}$ Gonçalves A.L., Lírio A.V., Graça M.A.S. \& Canhoto C. 2016. Fungal species diversity affects leaf decomposition after drought. Int. Rev. Hydrobiol. 101: 78-86

${ }^{23}$ Gulis V., Ferreira V. \& Graça M.A.S. 2006 Stimulation of leaf litter decomposition and associated fungi and invertebrates by moderate eutrophication: implications for stream assessment. Freshwat. Biol. 51: 1655-1669

${ }^{24}$ Ferreira V., Castela J., Rosa P., Tonin A.M., Boyero L. \& Graça M.A.S. 2016. Aquatic hyphomycetes, benthic macroinvertebrates and leaf litter decomposition in streams naturally differing in riparian vegetation. Aq. Ecol. 50: 711-725

${ }^{25}$ Seena S., Carvalho F., Cássio F. \& Pascoal C. 2017. Does the developmental stage and composition of riparian forest stand affect ecosystem functioning in streams? Sci. Total Environ. 609: 1500-1511

${ }^{26}$ Sridhar K.R., Duarte S., Cássio F. \& Pascoal C. 2009. The role of early fungal colonizers in leaf-litter decomposition in Portuguese streams impacted by agricultural runoff. Int. Rev. Hydrobiol. 94: 399-409

${ }^{27}$ Duarte S., Pascoal C. \& Cássio F. 2008. High diversity of fungi may mitigate the impact of pollution on plant litter decomposition in streams. Microb. Ecol. 56: 688-695

${ }^{28}$ Zeglin L.H. 2015. Stream microbial diversity in response to environmental changes: review and synthesis of existing research. Front. Microbiol. 6: 454

${ }^{29}$ Suberkropp K. 1998. Microorganisms and organic matter decomposition. Springer. USA, New York

${ }^{30}$ Bärlocher F. 2005. Freshwater fungal communities. In: Dighton J., White J. F. \& Oudemans $\mathrm{P}$ (eds.). The fungal community. Its organization and role in the ecosystem 3rd ed., Taylor and Francis, CRC Press. USA, Boca Raton, Florida, pp. 39-59

${ }^{31}$ Ingold C.T. 1942. Aquatic hyphomycetes of decaying alder leaves. Trans. Br. Mycol. Soc. 25: 339-417

${ }^{32}$ Gulis V., Marvanová L. \& Descals E. 2005. An illustrated key to the common temperate species of aquatic hyphomycetes. In: Graça M.A.S., Bärlocher F. \& Gessner M.O. (eds.) Methods to study litter decomposition: a practical guide. Springer. The Netherlands, Dordrecht, pp. 153-167

${ }^{33}$ Duarte S., Pascoal C., Garabétian F., Cássio F. \& Charcosset J.-Y. 2009. Microbial decomposer communities are mainly structured by trophic status in circumneutral and alkaline streams. Appl. Environ. Microbiol. 75: 6211-6221

${ }^{34}$ Duarte S., Pascoal C., Alves A., Correia A. \& Cássio F. 2010. Assessing the dynamic of microbial communities during leaf decomposition in a low-order stream by microscopic and molecular techniques. Microbiol. Res. 165: 351-362

35 Ferreira V. \& Canhoto C. 2015. Future increase in temperature may stimulate litter decomposition in temperate mountain streams: evidence from a stream manipulation experiment. Freshwat. Biol. 60: 881-892

${ }^{36}$ Canhoto C. \& Graça M.A.S. 1996. Decomposition of Eucalyptus globulus leavesand three native leaf species (Alnus glutinosa, Castanea sativa and Quercus faginea) in a Portuguese low order stream. Hydrobiologia 333: 79-85 
${ }^{37}$ Mesquita A., Pascoal C. \& Cássio F. 2007. Assessing effects of eutrophication in streams based on breakdown of eucalypt leaves. Arch. Hydrobiol. 168: 221-230

${ }^{38}$ Bärlocher F., Kebede Y.K., Gonçalves A.L. \& Canhoto C. 2013. Incubation temperature and substrate quality modulate sporulation by aquatic hyphomycetes. Microb. Ecol. 66: 30-39

${ }^{39}$ Ferreira V., Raposeiro P.M., Pereira A., Cruz, A.M. Costa, A.C. Graça, M.A.S. \& Gonçalves V. 2016. Leaf litter decomposition in remote oceanic island streams is driven by microbes and depends on litter quality and environmental conditions. Freshwat. Biol. 61: 783-799

${ }^{40}$ Ferreira V. \& Graça M.A.S. 2016. Effects of whole-stream nitrogen enrichment and litter species mixing on litter decomposition and associated fungi. Limnologica 58: $69-77$

${ }^{41}$ Ferreira V., Elosegi A., Gulis V., Pozo J. \& Graça M.A.S. 2006. Eucalyptus plantations affect fungal communities associated with leaf-litter decomposition in Iberian streams. Arch. Hydrobiol. 166: 467-490

${ }^{42}$ Fernandes I., Uzun B., Pascoal C. \& Cássio F. 2009. Responses of aquatic fungal communities on leaf litter to temperature-change events. Internat. Rev. Hydrobiol. 94: $410-418$

43 Pascoal C., Cássio F. \& Marvanová L. 2005. Anthropogenic stress may affect aquatic hyphomycete diversity more than leaf decomposition in a low-order stream. Arch. Hydrobiol. 162: 481-496

${ }^{44}$ Duarte S., Bärlocher F., Trabulo J., Cássio F. \& Pascoal C. 2015. Stream-dwelling fungal decomposer communities along a gradient of eutrophication unraveled by 454 pyrosequencing. Fungal Div. 70: 127-148

${ }^{45}$ Castela J., Ferreira V. \& Graça M.A.S. 2008. Evaluation of stream ecological integrity using litter decomposition and benthic invertebrates. Environ. Poll. 153: 440-449

${ }^{46}$ Ferreira V., Gulis V. \& Graça M.A.S. 2006. Whole-stream nitrate addition affects litter decomposition and associated fungi but not invertebrates. Oecologia 149: 718-729

${ }^{47}$ Duarte S., Pascoal C., Alves A., Correia A. \& Cássio F. 2008. Copper and zinc mixtures induce shifts in microbial communities and reduce leaf litter decomposition in streams. Freshwat. Biol. 53: 91-101

${ }^{48}$ Ferreira V., Chauvet E. \& Canhoto C. 2015. Effects of experimental warming, litter species, and presence of macroinvertebrates on litter decomposition and associated decomposers in a temperate mountain stream. Can. J. Fish. Aquat. Sci. 72: 206-216

${ }^{49}$ Ingold C.T. 1949. Aquatic hyphomycetes from Switzerland. Trans. Br. Mycol. Soc. 32: $341-345$

${ }^{50}$ Ingold C.T. 1956. Stream spora in Nigeria. Trans. Br. Mycol. Soc. 39: 108-110

${ }^{51}$ Ingold C.T. 1960. Aquatic hyphomycetes from Canada. Can. J. Bot. 38: 803-806

${ }^{52}$ Duarte S., Bärlocher F., Pascoal C. \& Cássio F. 2016. Biogeography of aquatic hyphomycetes: current knowledge and future perspectives. Fungal Ecol. 19: 169-181

${ }^{53}$ Shearer C.A., Descals E., Kohlmeyer B., Kohlmeyer J., Marvanová L., Padgett D., Porter D., Raja H.A., Schmit J.P., Thorton H.A. \& Voglymayr H. 2007. Fungal biodiversity in aquatic habitats. Biodivers. Conserv. 16: 49-67 
${ }^{54}$ Bärlocher F. \& Graça M.A.S. 2002. Exotic riparian vegetation lowers fungal diversity but not leaf decomposition in Portuguese streams. Freshwat. Biol. 47: 1123-1135

55 Pascoal C., Marvanová L. \& Cássio F. 2005. Aquatic hyphomycete diversity in streams of Northwest Portugal. Fungal Div. 19: 109-128

${ }^{56}$ Medeiros A., Duarte S., Pascoal C., Cássio F. \& Graça M.A.S. 2010. Effects of Zn, Fe and Mn on leaf litter breakdown by aquatic fungi: a microcosm study. Int. Rev. Hydrobiol. 95: 12-26

${ }^{57}$ Marvanová L., Pascoal C. \& Cássio F. 2003. New and rare hyphomycetes from streams of northwest Portugal. Part I. Cryptogamie. Mycologie 24: 339-358

${ }^{58}$ Descals E. 1989. Aquatic hyphomycetes. Preliminary key to the British "Ingoldian aquatic hyphomycetes". In: BMS Workshop on aquatic hyphomyctes. UK, Sheffield

${ }^{59}$ Sampaio A., Cortes R. \& Leão C. 2004. Yeast and macroinvertebrate communities associated with leaf litter decomposition in a second order stream. Int. Rev. Hydrobiol. 89: 453-466

${ }^{60}$ Sampaio A., Sampaio J.P. \& Leão C. 2007. Dynamics of yeast populations recovered from decaying leaves in a nonpolluted stream: a 2-year study on the effects of leaf litter type and decomposition time. FEMS Yeast Res. 7: 595-603

${ }^{61}$ Geesey G.G., Mutch R., Costerton J.W. \& Green R.B. 1978. Sessile bacteria: an important component of the microbial population in small mountain streams. Limnol. Oceanogr. 23: 1214-1223

${ }^{62}$ Findlay S., Strayer D., Goumbala C. \& Gould K. 1993. Metabolism of streamwater dissolved organic carbon in the shallow hyporheic zone. Limnol. Oceanogr. 38: 1493-1499

${ }^{63}$ Duarte S., Cássio F., Ferreira V., Canhoto C. \& Pascoal C. 2016. Seasonal variability may affect microbial decomposers and leaf decomposition more than warming in streams. Microb. Ecol. 72: 263-276

${ }^{64}$ Pradhan A., Seena S., Pascoal C. \& Cássio F. 2011. Can metal nanoparticles be a threat to microbial decomposers of plant litter in streams? Microb. Ecol. 62: 58-68

${ }^{65}$ Dunck B., Lima-Fernandes E., Cássio F., Cunha A., Rodrigues L. \& Pascoal C. 2015. Responses of primary production, leaf litter decomposition and associated communities to stream eutrophication. Environ. Poll. 202: 32-40

${ }^{66}$ Pereira A., Geraldes P., Lima-Fernandes E., Fernandes I., Cássio F. \& Pascoal C. 2016. Structural and functional measures of leaf-associated invertebrates and fungi as predictors of stream eutrophication. Ecol. Ind. 69: 648-656

${ }^{67}$ Pereira A., Trabulo J., Fernandes I., Pascoal C., Cássio F. \& Duarte S. 2017. Spring stimulates leaf decomposition in moderately eutrophic streams. Aq. Sci. 79: 197-207

${ }^{68}$ Fernandes I., Seena S., Pascoal C. \& Cássio F. 2014. Elevated temperature may intensify the positive effects of nutrients on microbial decomposition in streams. Freshwat. Biol. 59: 2390-2399

${ }^{69}$ Dang C. K., Schindler M., Chauvet E. \& Gessner M.O. 2009. Temperature oscillation coupled with fungal community shifts can modulate warming effects on litter decomposition. Ecology 90: 122-131

${ }^{70}$ Duarte S., Fernandes I., Nogueira M.J., Cássio F. \& Pascoal C. 2013. Temperature alters interspecific relationships among aquatic fungi. Fungal Ecol. 6: 187-191 
${ }^{71}$ Ferreira V. Chauvet E. \& Canhoto C. 2014. Effects of experimental warming, litter species, and presence of macroinvertebrates on litter decomposition and associated decomposers in a temperate mountain stream. Can.J. Fish. Aq. Sci. 72: 206-216

${ }^{72}$ Ferreira V. \& Canhoto C. 2015. Future increase in temperature may stimulate litter decomposition in temperate mountain streams: evidence from a stream manipulation experiment. Freshwat. Biol. 60: 881-892

${ }^{73}$ Domingos C., Ferreira V., Canhoto C. \& Swan C. 2015. Warming, and the presence of a dominant shredder, drive variation in decomposer communities in a mountain stream. Aq. Sci. 77: 129-140

${ }^{74}$ Ferreira V., Encalada A.C. \& Graça M.A.S. 2012. Effects of litter diversity on decomposition and biological colonization of submerged litter in temperate and tropical streams. Freshwat. Sci. 31: 945-962

${ }^{75}$ Fernandes I., Seena S., Pascoal C. \& Cássio F. 2014. Elevated temperature may intensify the positive effects of nutrients on microbial decomposition in streams. Freshwat. Biol. 59: 2390-2399

${ }^{76}$ Lima-Fernandes E., Fernandes I., Geraldes P., Pereira A., Cássio F. \& Pascoal C. 2015. Eutrophication modulates plant-litter diversity effects on litter decomposition in streams. Freshwat. Sci. 34: 31-41

${ }^{77}$ Fernandes I., Pascoal C., Guimarães H., Pinto R., Sousa I. \& Cássio F. 2012. Higher temperature reduces the effects of litter quality on decomposition by aquatic fungi. Freshwat. Biol. 57: 2006-2317

${ }^{78}$ Graça M.A.S., Pozo J., Canhoto C. \& Elosegi A. 2002. Effects of Eucalyptus plantations on detritus, decomposers and detritivores in streams. The Scientific World J. 2: 1173-1185

${ }^{79}$ Fernandes I., Duarte S., Cássio F. \& Pascoal C. 2013. Effects of riparian plant diversity loss on aquatic microbial decomposers become more pronounced with increasing time. Microb. Ecol. 66: 763-772

${ }^{80}$ Ferreira V., Koricheva J., Pozo J. \& Graça M.A.S. 2016. A meta-analysis on the effects of changes in the composition of native forests on litter decomposition in streams. Forest Ecol. Manag. 364: 27-38

${ }^{81}$ Ferreira V., Larrañaga A., Gulis V., Basaguren A., Elosegi A., Graça M.A.S. \& Pozo J. 2015. The effects of eucalypt plantations on plant litter decomposition and macroinvertebrate communities in Iberian streams. Forest Ecol. Manag. 335: 129-138

${ }^{82}$ Canhoto C, Abelho M. \& Graça MA.S. 2001. Effects of Eucalyptus globulus plantations in low order streams of central Portugal. In: Pardal M.A., Marques J.C. \& Graça M.A.S. (eds.) Aquatic ecology of the Mondego River basin global importance of local experience. Imprensa da Universidade de Coimbra. Portugal, Coimbra, pp. 505-514

${ }^{83}$ Bärlocher F., Canhoto C. \& Graça M.A.S. 1995. Fungal colonization of alder and eucalypt leaves in two streams in central Portugal. Arch. Hidrobiol. 133: 457-470

${ }^{84}$ Ferreira V., Faustino H., Raposeiro P.M. \& Gonçalves V. 2017. Replacement of native forests by conifer plantations affects fungal decomposer community structure but not litter decomposition in Atlantic island streams. Forest Ecol. Manag. 389: $323-330$

${ }^{85}$ Duarte S., Pascoal C. \& Cássio F. 2004. Effects of zinc on leaf decomposition by fungi in streams: studies in microcosms. Microb. Ecol. 48: 366-374 
${ }^{86}$ Sridhar K.R., Krauss G., Bärlocher F., Raviraja N.S., Wennrich R., Baumbach R. \& Krauss G.-J. 2001. Decomposition of alder leaves in two heavy metal-polluted streams in central Germany. Aquat. Microb. Ecol. 26: 73-80

${ }^{87}$ Pascoal C., Cássio F., Nikolcheva L. \& Bärlocher F. 2010. Realized fungal diversity increases functional stability of leaf litter decomposition under zinc stress. Microb. Ecol. 59: 84-93

${ }^{88}$ Moreirinha C., Duarte S., Pascoal C. \& Cássio F. 2011. Effects of cadmium and phenanthrene mixtures on aquatic fungi and microbially mediated leaf litter decomposition. Arch. Environ. Contam. Toxicol. 61: 211-219

${ }^{89}$ Garner K.L. \& Keller A.A. 2014. Emerging patterns for engineered nanomaterials in the environment: a review of fate and toxicity studies. J. Nanoparticle Res. 16: 2503

${ }^{90}$ Pradhan A., Geraldes P., Seena S., Pascoal C. \& Cássio F. 2016. Humic acid can mitigate the toxicity of small copper oxide nanoparticles to microbial decomposers and leaf decomposition in streams. Freshwat. Biol. 61: 2197-2210

${ }^{91}$ Pradhan A., Seena S., Pascoal C. \& Cássio F. 2012. Copper oxide nanoparticles can induce toxicity to the freshwater shredder Allogamus ligonifer. Chemosphere 89: $1142-1150$

${ }^{92}$ Batista D., Pascoal C. \& Cássio F. 2017. How do physicochemical properties influence the toxicity of silver nanoparticles on freshwater decomposers of plant litter in streams? Ecotoxicol. Environ. Safety 140: 148-155

${ }^{93}$ Batista D., Pascoal C. \& Cássio F. 2017. Temperature modulates AgNP impacts on microbial decomposer activity. Sci. Total Environ. 601: 1324-332

${ }^{94}$ Arnold K.E., Brown A.R., Ankley G.T. \& Sumpter J.P. 2014. Medicating the environment: assessing risks of pharmaceuticals to wildlife and ecosystems. Phil. Trans. R. Soc. B 369: 20130569

95Ferrando-Climent L., Rodriguez-Mozaz S. \& Barceló D. 2014. Incidence of anticancer drugs in an aquatic urban system: from hospital effluents through urban wastewater to natural environment. Environ. Poll. 193: 216-223

${ }^{96}$ Proia L., Cássio F., Pascoal C., Tlili A. \& Romaní A.M. 2012. The use of attached microbial communities to assess ecological risks of pollutants in river ecosystems: the role of heterotrophs. In: Guasch H., Ginebreda A. \& Geiszinger A. (Eds.) Emerging and Priority Pollutants in Rivers. Springer-Verlag. Germany, Berlin Heidelberg, pp. 55-83

${ }^{97}$ Seena S., Duarte S., Pascoal C. \& Cássio F. 2012. Intraspecific variation of the aquatic fungus Articulospora tetracladia: an ubiquitous perspective. PLoS One 7: e35884

${ }^{98}$ Fernandes I., Pascoal C. \& Cássio F. 2011. Intraspecific traits change biodiversity effects on ecosystem functioning under metal stress. Oecologia 166: 1019-1028 